\title{
Pierre-Jean Dufief, Les Goncourt moralistes
}

\section{Marco Garrone}

\section{(2) OpenEdition}

\section{Journals}

\section{Edizione digitale}

URL: https://journals.openedition.org/studifrancesi/38102

DOI: 10.4000/studifrancesi.38102

ISSN: 2421-5856

\section{Editore}

Rosenberg \& Sellier

\section{Edizione cartacea}

Data di pubblicazione: 15 décembre 2004

Paginazione: 638-639

ISSN: 0039-2944

\section{Notizia bibliografica digitale}

Marco Garrone, «Pierre-Jean Dufief, Les Goncourt moralistes», Studi Francesi [Online], 144 (XLVIII | III) | 2004, online dal 30 novembre 2015, consultato il 08 mai 2021. URL: http://journals.openedition.org/ studifrancesi/38102 ; DOI: https://doi.org/10.4000/studifrancesi.38102

\section{Questo documento è stato generato automaticamente il 8 mai 2021.}

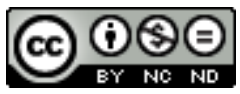

Studi Francesi è distribuita con Licenza Creative Commons Attribuzione - Non commerciale - Non opere derivate 4.0 Internazionale. 


\title{
Pierre-Jean Dufief, Les Goncourt moralistes
}

\author{
Marco Garrone
}

\section{NOTIZIA}

PIERRE-JEAN DUFIEF, Les Goncourt moralistes, «Travaux de Littérature», XIII, 2001, pp.

217-226

1 La questione era già stata sollevata in passato da Ernest Seillière: il suo saggio Les Goncourt motalistes, tuttavia, non aveva mantenuto la promessa implicita nel titolo, cioè non aveva saputo illustrare la ragione per cui i fratelli "inventori" del naturalismo potessero in qualche modo essere accostati ai grandi moralisti del XVII secolo. L'A. decide quindi di riproporre tale teoria e nell'argomentazione della propria tesi non può che partire dal ricordare come i fratelli stessi furono, fin da giovani, fervidi ed instancabili lettori dei moralisti classici.

2 Proprio negli anni in cui i G. scrivevano, l'opera di Vinet e di Prévost-Paradol aveva avuto il merito di aver dato una delle prime e più autorevoli definizioni di "moralista", identificandone i mezzi - tra tutte la forma breve - ed i tratti caratteristici essenziali. I più grandi moralisti della tradizione classicista francese (vengono citati naturalmente Vauvenargues, che i fratelli tuttavia non amano, La Rochefoucauld, La Bruyère, Joubert et Chamfort) occupano un posto d'eccellenza nella biblioteca dei due fratelli, che non solo li leggono e li apprezzano, ma che da grandi bibliofili ne ricercano i manoscritti, gli inediti e le pubblicazioni rare. Particolare rilievo viene poi dato alla grande ammirazione dei G. per il già citato La Bruyère che, secondo loro, con una sola pagina dei suoi Caractères, era stato in grado di cogliere la vera natura dell'uomo più di quanto fossero riusciti a fare altri autori suoi contemporanei con centinaia e centinaia di versi. Di La Bruyère, precisa l'A., Edmond e Jules apprezzavano inoltre il carattere ironico, l'originalità e la tendenza innata al paradosso pungente. Ciò influenzò estremamente la scrittura ed il pensiero dei G. che, seppur dotati di una grande sensibilità visiva, non si 
limitarono ad osservare e a descrivere, ma si spinsero otre, valutando e giudicando: il loro Journal, alla luce di quanto è stato detto, può di conseguenza essere letto sia come un semplice quaderno d'annotazioni, di descrizioni ed impressioni scaturite da situazioni vissute personalmente, sia e soprattutto come raccolta di massime. Queste ultime, è importante dire, si organizzano spesso come "contro-massime", diventando cioè modifiche e rielaborazioni attualizzate di massime già esistenti.

La ragione per cui non si è mai riconosciuto ufficialmente questa dimensione di "penseurs" dei G. è da ricercare essenzialmente nel fatto che nelle loro opere risulta difficile trovare una riflessione filosofica organica e strutturata secondo i canoni filosofici classici: come è noto i fratelli diffidavano dai sillogismi vuoti, dalle teorie sterili e dai discorsi fiume dei professori e dei logici. Come lo stesso Valéry aveva fatto notare, il moralista è continuamente in rapporto con il reale ed il concreto, ed è proprio questo che i G. fanno: essi avvicinano in continuazione il concreto accostandolo all'astratto, facendo convergere l'impressione all'idea, congiungendo i limiti opposti dei due poli dell'arte, quello visivo e quello intellettuale. Attraverso il gusto personale per le massime, i fratelli ignorano la menzogna e strappano ogni maschera per cogliere il lato amaro delle cose, quel lato amaro che in seguito, proprio come facevano i moralisti, essi rappresenteranno con colori assolutamente pessimistici. I G. credono nella demistificazione di ogni falso valore in cui la nostra società presta fede e che è stato spesso appoggiato dalle illusioni e dalle menzogne fomentate da correnti come l'idealismo e il romanticismo. A colpi di massime e sentenze tutto (come avviene con l'amore, la natura, la religione, l'onore), è dunque rivalutato e se necessario ridimensionato o distrutto.

Come i moralistes classici, i fratelli G. non organizzano i propri discorsi in vasti periodi; le loro opere molto spesso si presentano come un mosaico di periodi brevi, di epigrammi, di calembours che costituiscono testimonianze di esperienze e conversazioni colte dalla vivo. Questa vena moralista, che verrà ad indebolirsi in seguito alla morte di Jules, è comunque contestualizzata e risente dell'influenza dell'epoca: conciliandosi con il gusto del reale, tali "contro-massime" si omogeneizzano ai tratti distintivi di quella "letteratura di miopi" così ossessionata dal dettaglio di cui i fratelli rappresentavano $i$ precursori e i cui soli epigoni trassero i meriti e i successi.

5 L'A. sottolinea in conclusione come, in fondo, nel moralismo dei fratelli G. non ci sia esclusivamente una semplice volontà estetica. Al pari degli stessi moralisti, anche gli autori del Journal, impugnando la forma breve, esprimono il desiderio di criticare e dominare le coscienze altrui. Come pure Doubrovsky aveva notato nei moralisti classici, anche i fratelli, il cui valore letterario era stato riconosciuto tardivamente, decisero più o meno consciamente di affermare, attraverso la scrittura, la propria posizione dominante sia sul piano intellettuale che su quello morale, alla ricerca della vendetta nei confronti di un mondo che li ignorava. 